\title{
Editorial
}

\section{Tiago Fazeres-Ferradosa}

CIIMAR - Interdisciplinary Centre of Marine and Environmental Research of the University of Porto, Marine Energy Research Group, Porto, Portugal (tferradosa@fe.up.pt)

\section{Francisco Taveira-Pinto}

Hydraulics, Water Resources and Environmental Division, Department of Civil Engineering, Faculty of Engineering of the University of Porto, Porto, Portugal

\section{Paulo Rosa-Santos}

CIIMAR - Interdisciplinary Centre of Marine and Environmental Research of the University of Porto, Porto, Portugal; Habilitation/Aggregation division, Department of Civil Engineering, FEUP - Faculty of Engineering of the University of Porto, Porto, Portugal

\section{Victor Ramos}

CIIMAR - Interdisciplinary Centre of Marine and Environmental Research of the University of Porto, Marine Energy Research Group, Porto, Portugal
The complexity of the marine environment and the uncertainty of placing structures and systems at nearshore and offshore locations has systematically opened different lines of research and ground-breaking applications that represent remarkable milestones in the relationship of humankind with the sea. Ports and harbours, novel sea energy harvesting technologies and offshore platforms are clear examples of such fields of research and practical engineering. The present issue of Maritime Engineering compiles a set of novel works on such topics. This represents a continuity of former issues published on similar applications and case studies, the most recent ones being Correia et al., (2019, 2019b, 2020, 2020b) and FazeresFerradosa et al., (2019, 2020).

A key topic of research on marine structures is the analysis of fatigue induced instability. Such research lines becomes particularly important when it comes to designing a wide variety of offshore structures and devices, from oil and gas platforms (e.g. Wang et al., 2017, Mourão et al., 2019) to wind energy structures (e.g. Campos et al., 2016), or even wave energy converters and other dynamic devices in sea conditions (e.g. FazeresFerradosa et al., 2021). In this issue, Shabakhty et al., (2021) provide a detailed investigation on the fatigue damage calibration factors for offshore structures, which are crucial for further fatigue ultimate state analysis and the study of other design and damage components, such as dynamic behaviour and crack propagation estimates. Shabakhty et al. (2021) estimate the fatigue damage on tubular steel members and respective joint location, typical of a common offshore platform as a jacket or tower type structure. The damage is estimated based on an initial size crack, whose propagation growth is analysed in surface and depth of the tubular steel member. The S-N curves obtained from the fracture mechanics crack propagation method are compared between two standards, the DNVGL-RPC203 and the API-RP2A-WSD (DNVGL, 2014 and API, 2014). The authors show that both standards show considerable deviations between their S-N curves, thus justifying the need to properly calibrate the fatigue damage factors. New calibration factors are proposed while the effects of initial crack depth and the critical crack depth are found to significantly affect the determination of the calibration factors. The present work provides an interesting comparison between widely used standards, highlighting differences in fatigue damage estimation that ultimately affect the overall layout and costs associated to such practical wonders of maritime engineering.

As widely showed by former research developed on extreme phenomena and extreme response of marine structures and systems, the introduction of more accurate models to obtain design environmental loads is also another critical aspect for design, operation and maintenance aspects (e.g. FazeresFerradosa et al., 2018). This has been recently shown and addressed by Maritime Engineering latest publications, for example in Hames et al., (2019, 2020), Myrhaug and Lader (2021) or Vanem et al., (2019). Therefore, updated models to establish load conditions remain as an important requirement in the scientific and professional literature. This becomes even more evident in light of the climate change scenarios and the need to properly model joint events. Regarding this topic, Wang (2021) addresses the extreme dynamic response of wave energy converters (WECs) by introducing a novel nonparametric copula-based method to derive the environmental contours required to estimate extreme responses. In this article, the statistical modelling of met-ocean conditions is combined with the design needs of WECs, which is another research line of growing importance, as recently reviewed in Taveira-Pinto et al., (2020). The novel method outperforms commonly used models in the literature for similar purposes, namely, the broadly diffused models based on Clayton and Gumbel copulas. In this case, the authors propose a bi-variate kernel density estimation approach to generate the design environmental contours. The method is then validated using a WEC device for two offshore locations, one near the southeast of Portland (Maine, USA) and the other one near the southeast of Nantucket (USA). This study shows that environmental design values can vary up to almost $16 \%$ with the new model when compared to the ones formerly applied. Hence, this article is an interesting application for future research on the met-ocean statistics applied to offshore WECs for both design and optimisation purposes. 
Finally, moving a bit closer to shore, Cooper et al., (2021) provide a very interesting analysis of the famous centenary Whitby Harbour and its $£ 6.76$ million refurbishment of the west and east piers at the mouth of the River Esk estuary (North Yorkshire, UK). This is indeed a unique practical case study with high value for further applications in similar harbour infrastructures, which are key locations of anthropogenic pressure in coastal areas (Taveira-Pinto et al., 2020b, 2021). This article is aligned with former contributions for Maritime Engineering with a particular focus on emblematic field cases, for example Bolle et al., (2015), Reedijk et al. (2015) or Melchers and Howlett (2021) among numerous others. Cooper et al., (2021) give a detailed analysis of the refurbishment works carried out, including a parallel analysis of the heritage related to the harbour, which in one form or another has a history of about 800 years. The project's work included the stabilization of the sandstone facing blocks, voids' filling, deck surface repairments and the inclusion of a new flood deflector wall for flooding protection. Flooding phenomena were quite recurrent at the location and the new flood deflector was given as an alternative solution to the more visually intrusive flood gate alternative. Description of the marine operations carried under hostile marine environment is given, with detailed reference on actions taken, equipment and operation planning elements. The physical setting and historic development of the harbour at Whitby is analysed and the authors draw lessons from an earlier refurbishment of another grade II listed marine structure. As a result, these lessons were applied to the refurbishment of the Whitby harbour piers to ensure that the works remained sensitive to the heritage values and iconic aesthetic setting of the area. Hence, this article reveals itself as an interesting case study, not only for maritime engineering purposes, but also for those who seek applications on heritage preservation and maintenance under adverse environmental conditions typical from coastal regions.

Either on remote locations or closer to shore, marine structures and systems remain as an appealing topic in maritime engineering. These recent contributions show that there is still an evident need for research and development encompassing numerous aspects related to their design, maintenance and overall analysis. In this sense, the present issue aims to provide clear examples of some of the challenges and recent practical cases that can be used as a reference for future applications towards the enhancement of knowledge related to Marine Structures and Systems, which are expected to continue growing for the next decades to come.

\section{REFERENCES}

API (2014) API-RP2A-WSD: Planning, designing, and constructing fixed offshore platforms - working stress design. API, Washington DC, USA.

Bolle A, das Neves L and Rooseleer J (2015) Coastal protection for Ada, Ghana: A case study. Proceedings of the Institution of Civil
Engineers: Maritime Engineering 168(3): 125-133, https://doi. org/10.1680/jmaen.15.00013.

Campos A, Molins C, Gironella X and Trubat P (2016) Spar concrete monolithic design for offshore wind turbines. Proceedings of the Institution of Civil Engineers: Maritime Engineering 169(2): 49-63, https://doi.org/10.1680/jmaen.2014.24.

Cooper N, Stewart R, Burdett S, Dewe G and Cooper V (2021) The heritage and refurbishment of rgade II listed piers at Whitby harbour, North Yorkshire. Proceedings of the Institution of Civil Engineers: Maritime Engineering 174(3): 91-99, https://doi.org/10. 1680/jmaen.2020.22.

Correia JAFO, Fazeres-Ferradosa T, Zhu S and Zhu S (2020b) Renewable Energy and Oceanic Structures: Part IV. Proceedings of the Institution of Civil Engineers: Maritime Engineering 173(2): 31-32, https://doi.org/10.1680/jmaen.2020.173.2.30.

Correia JAFO, Ferradosa T, Castro JM, Fantuzzi N and Jesus AMPD (2019) Editorial: Renewable energy and oceanic structures: Part I. Proceedings of the Institution of Civil Engineers: Maritime Engineering 172(1): 1-2, https://doi.org/10.1680/ jmaen.2019.172.1.1.

Correia JAFO, Ferradosa T, Castro JM, Pavlou DG and De Jesus AMP (2019b) Editorial: Renewable Energy and Oceanic Structures: Part II. Proceedings of the Institution of Civil Engineers: Maritime Engineering 172(3): 71-72, https://doi.org/10.1680/ jmaen.2019.172.3.71.

Correia JAFO, Mendes P, Fazeres-Ferradosa T and Zhu S-P (2020a) Renewable Energy and Oceanic Structures: Part III. Proceedings of the Institution of Civil Engineers: Maritime Engineering 173(1): 1-2, https://doi.org/10.1680/jmaen.2020.173.1.1.

DNV GL (2016) DNVGL-RP-C203: Fatigue design of offshore steel structures. DNV GL, Høvik, Norway.

Fazeres-Ferradosa T, Chambel J, Taveira-Pinto F et al. (2021) Scour Protections for Offshore Foundations of Marine Energy Harvesting Technologies: A Review. Journal of Marine Science and Engineering 9(3): 297, https://doi.org/10.3390/jmse9030297.

Fazeres-Ferradosa T, Rosa-Santos P, Taveira-Pinto F et al. (2019) Editorial: Advanced research on offshore structures and foundation design: Part 1. Proceedings of the Institution of Civil Engineers: Maritime Engineering 172(4): 118-123, https://doi.org/10.1680/jmaen.2019. 172.4.118.

Fazeres-Ferradosa T, Rosa-Santos P, Taveira-Pinto F et al. (2020) Preface: Advanced Research on Offshore Structures and Foundation Design: Part 2. Proceedings of the Institution of Civil Engineers: Maritime Engineering 173(4): 96-99, https://doi.org/10.1680/ jmaen.2020.173.4.96.

Fazeres-Ferradosa T, Taveira-Pinto F, Vanem E, Reis MT and das Neves L (2018) Asymmetric copula-based distribution models for met-ocean data in offshore wind engineering applications. Wind Engineering 42(4): 304-334, https://doi.org/10.1177/0309524X18777323.

Hames DP, Gouldby BP and Hawkes PJ (2019) Evolution of joint probability methods in coastal engineering practice in the UK. Proceedings of the Institution of Civil Engineers: Maritime Engineering 172(2): 45-54, https://doi.org/10.1680/jmaen.2019.4.

Hames DP, Gouldby BP and Hawkes PJ (2020) Investigating the use of joint probability curves in coastal engineering practice. Proceedings of the Institution of Civil Engineers: Maritime Engineering 173(3): 68-78, https://doi.org/10.1680/jmaen.2019.12.

Melchers RE and Howlett CM (2021) Reinforcement corrosion of the Phoenix caissons after 75 years of marine exposure. Proceedings of the Institution of Civil Engineers: Maritime Engineering 174(1): 19-30, https://doi.org/10.1680/jmaen.2019.19.

Mourão A, Correia JAFO, Ávila BV et al. (2020) A fatigue damage evaluation using local damage parameters for an offshore 
structure. Proceedings of the Institution of Civil Engineers: Maritime Engineering 173(2): 43-57, https://doi.org/10.1680/jmaen. 2019.24

Myrhaug D and Lader PF (2021) Random wave-induced current in shallow water using deep-water wind and wave statistics. Proceedings of the Institution of Civil Engineers: Maritime Engineering 174(1): 11-18, https://doi.org/10.1680/jmaen.2019.9.

Reedijk B, van't Zelfde A, Pieterse J-J, van Leeuwen M and Manaois JR (2015) Results from the Dutch Ecobeach pilot project. Proceedings of the Institution of Civil Engineers: Maritime Engineering 168(3): 134-141, https://doi.org/10.1680/jmaen.15.00023.

Shabakhty N, Correia JAFO and Haselibozchaloee D (2021) Investigation on fatigue damage calibration factors in offshore structures. Proceedings of the Institution of Civil Engineers: Maritime Engineering 174(3): 65-80, https://doi.org/10.1680/jmaen.2020.17.

Taveira-Pinto F, Rosa-Santos P and Fazeres-Ferradosa T (2020) Marine renewable energy. Renewable Energy 150: 1160-1164, https://doi.org/10.1016/j.renene.2019.10.014.

Taveira-Pinto F, Rosa-Santos P and Fazeres-Ferradosa T (2020b)

Anthropogenic influences on integrated coastal zone management
[Influências antropogénicas na gestão integrada da zona costeira] Journal of Integrated Coastal Zone Management 20(4): 215-217, https://doi.org/10.5894/rgci-n428.

Taveira-Pinto F, Rosa-Santos P and Fazeres-Ferradosa T (2021)

Coastal Dynamics and Protection. Journal of Integrated Coastal Zone Management 21(2): 69-72, https://doi.org/ 10.5894/rgci-n467.

Vanem E, Fazeres-Ferradosa T, Rosa-Santos P and Taveira-Pinto F (2019) Statistical description and modelling of extreme ocean wave conditions. Proceedings of the Institution of Civil Engineers: Maritime Engineering 172(4): 124-132, https://doi.org/10.1680/ jmaen.2019.20.

Wang $Y$ (2021) A new method for predicting the extreme dynamic responses of wave energy converters. Proceedings of the Institution of Civil Engineers: Maritime Engineering 174(3): 81-90, https://doi.org/10.1680/jmaen.2020.38.

Wang F, Dai L and Liang Z (2017) Effects of wave loads on the horizontal bracing strength of a semi-submersible platform. Proceedings of the Institution of Civil Engineers: Maritime Engineering 170(1): 21-31, https://doi.org/10.1680/jmaen.2016.27. 